\title{
INSTITUTOS PRIVADOS DE INVESTIGACIÓN "PURA" VERSUS POLÍTICAS PÚBLICAS DE CIENCIA Y TECNOLOGÍA EN LA ARGENTINA (1943-1955)
}

\author{
Diego Hurtado y María José Fernández \\ Centro de Estudios de Historia de la Ciencia José Babini. Universidad Nacional de San Martín. Buenos Aires \\ dhurtado2003@yahoo.com.ar
}

Recibido: 14 febrero 2012; Aceptado: 12 julio 2012.

\begin{abstract}
Cómo citar este artículo/ Citation: Hurtado, Diego; Fernández; María José (2013), "Institutos privados de investigación "pura" versus políticas públicas de ciencia y tecnología en la Argentina (1943-1955)", Asclepio, 65 (1): p010. doi: http://dx.doi.org/10.3989/asclepio.2013.10

RESUMEN: En junio de 1943 se produjo en la Argentina un golpe de Estado que inició un proceso de enfrentamientos entre un importante sector de científicos académicos y el gobierno militar de facto. Como resultado, muchos científicos perdieron sus cargos en las universidades, entre ellos el grupo liderado por el fisiólogo Bernardo Houssay, que iba a obtener el premio Nobel de Fisiología en 1947. A partir de ese momento, este grupo de médicos impulsaron la creación de una serie de institutos privados de investigación sostenidos por filántropos locales y por la Rockefeller Foundation. Este proceso continuó durante el gobierno democrático de Juan Perón (1946-1955). El presente artículo analiza este "proyecto" de creación de institutos privados -sus motivaciones y objetivoscomo un proceso de institucionalización "paralelo" y divergente respecto de las iniciativas impulsadas para la ciencia y la tecnología desde el sector público. Este "desdoblamiento" del proceso de institucionalización, encarnado en ideologías, modelos institucionales y jerarquías epistémicas difícilmente compatibles, iba a tener consecuencias de largo alcance para el futuro desarrollo de la investigación en la Argentina.
\end{abstract}

PALABRAS CLAVE: Proceso de institucionalización; Investigación pura; Houssay; Perón; Argentina.

\section{PRIVATE INSTITUTES OF “PURE” RESEARCH VERSUS PUBLIC POLICY ON SCIENCE AND TECHNOLOGY IN ARGENTINA (1943-1955)}

ABSTRACT: In June 1943 took place a coup d'etat in Argentina that initiated a process of confrontation between an important sector of academic scientists and the de facto military government. As a result, many scientists lost their positions at universities, between them a group of biomedical scientists led by the physiologist Bernardo Houssay, who was to be awarded the Nobel Prize in Physiology in 1947. From that moment on, supported by local philanthropists and the Rockefeller Foundation, Houssay's group began to promote the creation of a series of private research institutes. This process continued during the democratic government of Juan Perón (19461955). This article analyzes this "project" -its motivations and objectives - as a process of "parallel" institutionalization which was divergent from the initiatives promoted for science and technology by the public sector. This "splitting" of the institutionalization process, embodied in ideologies, institutional models and hardly compatible epistemic hierarchies, would have far-reaching consequences for the future development of research in Argentina.

KEY WORDS: Institutionalization process; Pure research; Houssay; Perón; Argentina.

Copyright: (c) 2013 CSIC. Este es un artículo de acceso abierto distribuido bajo los términos de la licencia Creative Commons Attribution-Non Commercial (by-nc) Spain 3.0. 


\section{INTRODUCCIÓN}

Durante la década de 1940 tuvo lugar en la Argentina un proceso de fragmentación política e ideológica que impactó en la incipiente conformación del complejo de instituciones de ciencia y tecnología. Con inflexiones propias, en las décadas siguientes esta disociación reprodujo la virulenta confrontación que la antinomia peronismo-antiperonismo instaló en la vida política argentina, justificó dictaduras militares y fue un factor determinante en el proceso de institucionalización de las actividades de ciencia y tecnología, así como de las políticas explícitas o implícitas -o de su ausencia- que lo guiaron.

Su manifestación más visible se expresó en el enfrentamiento entre dos representaciones del campo científico. Por un lado, una perspectiva guiada por una ideología que asignaba a las ciencias "puras" o a la "investigación fundamental" un lugar primario y que, por lo tanto, justificaba el reclamo de libertad de investigación en la elección de los temas a investigar, autonomía del Estado -o autorregulación de los científicos de sus propias actividades-, y búsqueda de estándares internacionales en la producción de conocimiento. Mientras que esta posición iba a ser defendida tenazmente en las décadas siguientes por algunos sectores o grupos de la comunidad científica argentina, por otro lado, algunas gestiones de gobierno y algunas instituciones públicas defendieron con diferentes grados de coherencia o énfasis una perspectiva que supuso que las actividades de investigación deben tener como meta final el desarrollo social y económico y que, por lo tanto, la ciencia y la tecnología debían integrarse a una política pública que les asignara la tarea de resolver "problemas nacionales". Como país en desarrollo, esto en general significaba trabajar en problemas vinculados a las áreas de energía, salud, recursos naturales, producción o defensa.

Si bien estas dos perspectivas, con comprensibles variantes determinadas por el contexto, estuvieron presentes en otras experiencias nacionales, la intensidad y persistencia del enfrentamiento político que tuvo lugar en la Argentina mantuvo vigente esta polarización a lo largo de por lo menos cuatro décadas. De esta forma, como marco amplio, el presente trabajo intenta dar cuenta de las primeras manifestaciones de esta disociación, analizando el período 19431955 , momento en que se consolidan dos proyectos de institucionalización de la ciencia desconectados y divergentes. En especial, el artículo analiza la creación y consolidación de una serie de institutos privados de investigación impulsados por un grupo de científicos reunidos en la Asociación Argentina para el Progreso de las Ciencias (AAPC). Estos eventos, que atraviesan el gobierno de facto que se inicia en junio de 1943, el siguiente período de democracia comprendido entre la llegada de Juan Perón a la presidencia, en mayo de 1946, y su derrocamiento por un nuevo golpe militar en septiembre de 1955, son concebidos en este artículo como un proceso de institucionalización paralelo a las iniciativas impulsadas dentro del ámbito estatal por el gobierno de Perón. Este desdoblamiento del proceso de institucionalización, encarnado en ideologías, modelos institucionales y jerarquías sociales y epistémicas divergentes, como dijimos, iba a tener consecuencias de largo alcance para el futuro desarrollo de la ciencia en la Argentina.

Finalmente, rasgos estructurales - de presencia evidente en nuestro objeto de estudio- como la inestabilidad política, la debilidad de los procesos de institucionalización, los altos costos de transacción o la dependencia disruptiva - ya sea económica, política o ideológica- de factores externos definen los rasgos determinantes del desarrollo científico en contextos periféricos. En este sentido, el presente trabajo también intenta mostrar de qué manera un fenómeno característico a partir del final de la Segunda Guerra Mundial, como fue la institucionalización de la política científica en los países avanzados, se manifiesta en la Argentina con las modulaciones y refracciones propias de los contextos periféricos.

\section{INSTITUCIONES Y RUPTURAS POLÍTICAS}

A comienzos de los años cuarenta, la AAPC - creada a fines de 1933- había logrado impulsar un sistema de becas y subsidios de investigación a partir de aportes de fuentes muy diversas, tanto públicas como privadas, tanto nacionales como extranjeras. Desde su creación, la AAPC se esforzaba por ganar visibilidad a través de la organización de conferencias o la publicación de folletos y artículos en diarios y publicaciones de lo más diversas. La retórica dominante solía desplegar diagnósticos críticos y reclamos de becas, subsidios, cargos full-time y mejores condiciones materiales en las universidades. Los argumentos giraban en torno a la comparación del escaso apoyo local con el decidido impulso que recibía la investigación en algunos países europeos o en los Estados Unidos. ${ }^{1}$

Durante su primera década de existencia, la AAPC logró un moderado reconocimiento social y político de sus actividades. En diciembre de 1937, por Ley sancionada por el Congreso y reglamentada por el Poder Ejecutivo, se entregaba a la AAPC títulos de renta nacional por la suma de 1 millón de pesos moneda nacional. Con las rentas producidas por este fondo y el número creciente de empresas que esperaban sumar a su red de filantropía, la asociación iba a ganar dimensión y continuidad (Houssay, 1964). ${ }^{2}$ Esta creciente visibilidad también significaba la consolidación del liderazgo de su presidente, el fisiólogo Bernardo Houssay, y del grupo de médicos investigadores que 
pertenecían a su círculo cercano. Ahora bien, a menos de diez años de creación de la AAPC un golpe de Estado alteró drásticamente los planes de expansión académica de este grupo.

El 4 de junio de 1943, un grupo de militares instaló un gobierno de facto de matriz nacionalista y antiliberal. La intervención de algunas universidades y la posición neutral sostenida por la Argentina frente a la Segunda Guerra Mundial desencadenó una respuesta de un grupo importante de intelectuales y profesores universitarios. El 15 de octubre de aquel año, algunos diarios argentinos publicaron un manifiesto firmado por un grupo de 150 intelectuales y profesores universitarios. "Democracia efectiva por medio de la fiel aplicación de todas las prescripciones de la Constitución Nacional y solidaridad americana por el leal cumplimiento de los compromisos internacionales firmados por los representantes del país", reclamaba el manifiesto a las autoridades militares. Al día siguiente, el secretario de la presidencia comunicó a los ministros que todos los firmantes debían ser "declarados cesantes en la administración nacional, reparticiones autárquicas inclusive" (Firmantes del Manifiesto, 1945, p. 5). ${ }^{3}$

Desde el Ministerio de Justicia e Instrucción Pública se impulsó una retórica maniquea que anunciaba la expulsión de sus puestos en las universidades de aquellos profesores y estudiantes que participaran de "propaganda o acciones subversivas" y que, además, serían susceptibles de recibir "sanciones de otra naturaleza" (Cortesi, 1943). Esta violenta reacción del gobierno puso en marcha un período de enfrentamientos entre un sector de la comunidad científica y académica y el gobierno de facto, que se extendió al período de gobierno democrático de Juan Perón (mayo de 1946-septiembre de 1955). Como veremos, esta confrontación tuvo amplia repercusión internacional y consecuencias de largo alcance en el proceso de institucionalización de la investigación científica en la Argentina.

La purga radical que tuvo lugar en las universidades, entre otras consecuencias, desbarató el proceso de expansión académica que venía desplegando desde comienzos de los años treinta el grupo del fisiólogo Bernardo Houssay. Desde 1919, Houssay dirigía el Instituto de Fisiología de la Facultad de Medicina de la Universidad de Buenos Aires. Al momento del golpe militar, la influencia directa de Houssay se extendía a las dos ciudades más importantes del país, luego de Buenos Aires: en Rosario, a través de Juan T. Lewis y Enrique Hug, ambos en la Universidad Nacional del Litoral (UNL); y en Córdoba, a través de Oscar Orías, en la Universidad Nacional de Córdoba (UNC). Buch caracteriza este despliegue como la conformación de "un trípode institucional que garantizó por una década la existencia de un poder disciplinario de carácter nacional con una enorme visibilidad internacional" (Buch, 2002, p. 396).

El golpe militar, con la expulsión de Houssay, Lewis y Orías de sus cargos universitarios, llevó a punto cero las posiciones institucionales y políticas ganadas por este grupo de científicos. Desde entonces, mientras que algunos científicos e ingenieros se dedicaban a explorar, sin mucho éxito, la posibilidad de crear una universidad "científica" privada al estilo de Stanford o Johns Hopkins como reacción a un escenario político y académico que los marginaba, el grupo de Houssay, con notable eficacia, comenzó a impulsar la creación de una serie de institutos privados de investigación. Esta iniciativa tuvo como condición de posibilidad la red de filantropía local que había ido conformando la AAPC desde su creación, el sostenido apoyo de la Rockefeller Foundation, ${ }^{4}$ así como la activa red de contactos internacionales de Houssay, utilizada para dar a conocer en foros internacionales la precaria situación en la que había quedado su grupo. Como se verá, el golpe militar favoreció el fortalecimiento de esta red, así como la visibilidad internacional de Houssay como víctima de un régimen autoritario, construcción que el propio fisiólogo ayudo a difundir y que se extendió al período de gobierno de Perón.

La decisión de impulsar la creación de institutos privados de investigación -iniciativa inédita América Latina- obligó a este grupo de científicos a enfrentar numerosos interrogantes: ¿cómo financiar la creación y sostenimiento de institutos privados de investigación?, ¿qué lugar había que dar a las fundaciones extranjeras?, ¿era posible sostener este proyecto a través de una estructura de filantropía local?, ¿qué grado de autonomía debía mantenerse respecto del Estado?, ¿qué modelos institucionales y organizacionales debían tomarse como referencia?, ¿cómo definir el compromiso social del científico? Las respuestas que este grupo fue esbozando - de manera explícita o implícita- a lo largo del proceso de materialización de estos institutos, junto a las representaciones del campo científico que fue elaborando en este trayecto, al quedar asociadas al "antiperonismo" oficial que una nueva dictadura impondría luego del derrocamiento de Perón, iban a marcar de forma irreversible el futuro de la investigación científica en la Argentina.

Mientras que ninguno de los proyectos de universidad "científica" privada pudo materializarse, en un contexto socio-político adverso de confrontación con las iniciativas oficiales por la legitimidad y el sentido social de la investigación, el grupo de Houssay logró impulsar la creación de una serie de cuatro institutos privados. A través de ellos, este grupo pudo continuar y diversificar sus líneas de investigación, consolidar sus redes de vinculación internacional, obtener a través de su principal figura el premio Nobel de fisiología y medicina y, con 
la caída de Perón a fines de 1955, quedar posicionado como el grupo de referencia sobre el que la nueva dictadura se iba a apoyar para impulsar el proyecto de creación de un consejo nacional de investigación, previa clausura de una institución peronista equivalente -la Dirección Nacional de Investigaciones Científicas y Técnicas (DNICYT) - , aunque orientada por una ideología diferente que daba prioridad a la resolución de los "problemas nacionales".

\section{UN DESTINO SUDAMERICANO}

Los sucesos posteriores al golpe militar de junio de 1943 se reflejaron en los principales diarios norteamericanos con titulares como "Argentina Widens 'Communist' Hunt", "Rebellion Grows Among Argentines", o volantas que señalaban "Nazis Are Free" (Cortesi, 1943). Este tratamiento de la prensa norteamericana no estaba disociado del conjunto de presiones que los Estados Unidos ejerció durante estos años sobre la Argentina - "oveja negra" del panamericanismo-, con el objeto de empujar a este país a una posición de relativo aislamiento y que, entre otras consecuencias, estuvo cerca de hacerle perder su membrecía en la recién creada Naciones Unidas (MacDonald, 1980, pp. 388-391).

En este escenario, Houssay fue objeto de la atención privilegiada de la prensa norteamericana, que dio cuenta de las repercusiones internacionales de su expulsión. La revista británica Nature y la norteamericana Science, así como algunos diarios norteamericanos trataron en sus páginas el caso de la expulsión de Houssay, quien a lo largo de los años de gobierno peronista iba a ser transformado en icono internacional de las persecuciones políticas ocurridas durante el gobierno de Perón (Science, 1944; Nature, 1946). Una nota en la primera plana del periódico norteamericano Christian Science Monitor sostenía:

“El Dr. Houssay, el científico natural más distinguido de la Argentina, cuyos logros han sido con frecuencia reconocidos en el exterior, es solo uno de los muchos que han establecido valientemente sus razones para rechazar una tregua con un régimen que consideran fascista y pro-nazi" (Hall Sharp, 1945, p. 1). ${ }^{5}$

La Rockefeller Foundation, que desde la década de 1920 había financiado las actividades de investigación fisiológica en la Argentina, especialmente las investigaciones de Houssay en el Instituto de Fisiología de la UBA (Cueto, 1994, pp. 132-133), dio respaldo político a la figura de Houssay frente al gobierno militar. Robert Lambert, director asociado de la Rockefeller Foundation era mencionado por la revista Science como responsable de haber enviado para su publicación la "declaración" de los 150 profesores argentinos, "incluido el científico sudamericano más destacado, Bernardo A. Houssay", documento reproducido junto con la réplica pública del gobierno argentino de facto en donde se anunciaba la cesantía de todos los firmantes (Science, 1943). Además del apoyo político y financiero de la Rockefeller Foundation, Houssay también contaba, como se verá, con el apoyo público de un grupo importante de científicos norteamericanos. De esta forma, la visibilidad internacional de Houssay fue un factor crucial para sostener su propósito inicial de crear un instituto privado para continuar con las investigaciones de su equipo.

En cuanto al apoyo local, la manifestación más importante surgió de la red de filantropía que la AAPC había comenzado a construir desde mediados de la década anterior para complementar los magros recursos públicos destinados a la investigación. Algunos pocos empresarios argentinos habían sido sensibles a los reclamos de la AAPC, y a comienzos de los años cuarenta ya existía una modesta red de filantropía local, en general basada en relaciones de amistad personal entre representantes del sector privado acaudalado y algunos miembros del colegiado de la AAPC. Estas iniciativas habían permitido alguna regularidad en la distribución de subsidios y la creación de un programa de becas internas y externas. ${ }^{6}$ Entre los testimonios más firmes de que existía, al menos entre 1935 y 1945, un sector empresario sensible a la actividad científica, se cuentan las donaciones de la Fundación Sauberán para el Fomento de las Investigaciones en Fisiología, orientadas, según los deseos expresados antes de su muerte por el propio Juan Bautista Sauberán, al estímulo de "la investigación científica original desinteresada y no al de la que es aplicada que será objeto de un ejercicio profesional retribuido" (Sauberán, 1936). ${ }^{7}$ Creada en 1944, a través de esta fundación se destinó la suma de 50.000 pesos nominales en títulos de Crédito Argentino interno para la creación del nuevo instituto de Houssay. La nueva fundación se colocó bajo la dependencia de la AAPC, depositaria del capital y garante del cumplimiento de las reglamentaciones, y su dirección quedó a cargo de una comisión formada por Lewis, encargado del manejo de los fondos de la donación, y de un abogado representante y consejero de la familia Sauberán. ${ }^{8}$

En los meses posteriores a su expulsión de la universidad, para Houssay resultaba claro que el gobierno militar estaba interesado en mantenerlo tan alejado como fuera posible de los ámbitos donde se desempeñaba normalmente (Houssay, $s / f$ ). Expulsado de la UBA, la red de contactos internacionales y la estructura que había montado la AAPC le permitieron a Houssay concebir, como reacción a esta situación, la creación de un instituto privado de investigación en donde continuar y expandir las actividades de su grupo. Es así que en marzo de 1944, con el apoyo de la Fundación Sauberán, de la Fundación Rockefeller y de la familia de su colaborador Eduardo Braun Menéndez 
- sexto hijo varón de una familia de pioneros colonizadores de la Patagonia- ${ }^{9}$ se concretó la creación del Instituto de Biología y Medicina Experimental (IByME), donde se instalaron los tres profesores titulares de fisiología de la UBA, la UNC y la UNL, Houssay, Orías y Lewis, y los dos suplentes, Eduardo Braun Menéndez y Virgilio Foglia (Houssay, 1989 [1956], p. 493). ${ }^{10}$ Houssay era conciente de la novedad del modelo de institución que impulsaba. En 1945 escribía:

"Este Instituto es una de las iniciativas más importantes realizadas en nuestro país para establecer un centro de investigaciones científicas desinteresadas de carácter privado e independiente de los recursos y la dirección del Gobierno o de sus dependencias" (Houssay, 1989 [1945], p. 178).

El nuevo laboratorio fue instalado en una casa ubicada en la ciudad de Buenos Aires, que había sido comprada por Mauricio Braun - padre de Eduardo Braun Menéndez- y sus hijos, "los cuales nos la facilitaron, sin cargo alguno, con una generosidad que obliga a nuestra eterna gratitud", cuenta Houssay. La familia Braun aportaba además "becas, donaciones anuales y valiosos consejos" (Houssay, 1959, p. 98).

En una carta dirigida a Louis Dexter - un discípulo de Harvard que anteriormente había viajado a Buenos Aires para capacitarse con él en la UBA-, Houssay explicaba que el IByME era "un pequeño laboratorio de investigaciones". Si bien "los recursos son escasos", habían decidido "no aceptar dinero sino de fuentes argentinas, para evitar interpretaciones malignas en este ambiente de mentirosos que nos rodea". Del exterior solamente aceptarían el financiamiento de aparatos o bibliografía (Houssay, 1944).

En este sentido, la pérdida de la biblioteca del Instituto de Fisiología de la UBA motivó varias iniciativas internacionales. En las páginas de la revista norteamericana Science se publicó una invitación a los "colegas norteamericanos" a colaborar con el nuevo instituto de Houssay enviándole sus publicaciones (Science, 1944),11 además de la difusión del llamado "Houssay Journal Fund" -impulsado por un comité integrado por Herbert Evans, Walter Cannon, John Fulton y Carl Wiggers-, que se propuso, con relativo éxito, reconstruir la biblioteca perdida del grupo de Houssay. Con este fin, además de promover el envío de colecciones de revistas, se lograron recolectar los fondos que hicieron posible que el fisiólogo argentino pudiera suscribirse a 18 publicaciones científicas norteamericanas de biología y fisiología, así como una suma de dinero para suscripciones a revistas de otros países (Cueto, 1994, p. 133; Science, 1945). ${ }^{12}$

Durante 1944, las donaciones sumaron aproximadamente \$136.000 (aproximadamente 34.000 dólares). Si bien la mayor parte de estos aportes provenían de la Fundación Sauberán y de la Rockefeller Founda- tion -en este último caso, solo para financiar aparatos e insumos-, también existían una cantidad de pequeñas colaboraciones que realizaban otros profesionales (Houssay, 1945a). ${ }^{13}$ Ahora bien, a pesar de los esfuerzos por consolidar una estructura de filantropía privada, en este momento ya era claro que, bajo la influencia de lo que estaba ocurriendo en los Estados Unidos al final de la guerra, las principales expectativas de Houssay se reorientaban hacia el financiamiento público y hacia la recuperación de su antiguo cargo en la UBA.

Cuando a comienzos de febrero de 1945 se promulgó un decreto de reincorporación de los profesores expulsados de las universidades en octubre de 1943 y se inició un breve período de recomposición política y normalización institucional, Houssay retornó al Instituto de Fisiología de la UBA. Motivado por el horizonte promisorio que presagiaba este viraje político, en junio, Houssay le escribía una carta a su discípulo Luis F. Leloir, que se encontraba en los Estados Unidos:

"Siempre he creído y persisto en creer que el porvenir científico de un país está ligado a la Universidad, en lo cual tengo discrepancias con el Dr. Braun Menéndez y la mayor parte de los jóvenes que están desilusionados de la Universidad y quieren que se funden universidades o laboratorios privados. Es muy difícil conseguir recursos permanentes para estos últimos" (Houssay, 1945b).

De vuelta en la UBA, Houssay había autorizado a Braun Menéndez a hacerse cargo de la dirección del IByME. Sin embargo, Houssay le reprochaba a sus colaboradores la división de esfuerzos: "No creo tan fácil como ustedes que se mantenga el Instituto de Biología y Medicina Experimental y no creo que su vida esté asegurada", le escribía a Orías. Houssay le explicaba que Braun Menéndez podría ser el director adecuado, aunque "al sacarlo de la Facultad debilitamos a ésta". Finalmente, también lo preocupaba el hecho de que podría necesitar para el instituto de la UBA fondos de la Fundación Sauberán, "y sería una lástima que no me los pudieran dar o que estuvieran en competencia los 2 Institutos". Y finalmente vaticinaba: "Ustedes creen que se puede mejorar al país sin mejorar a la Universidad. Quieren como el avestruz ignorar al mundo por poner la cabeza bajo el ala" (Houssay, 1945c). Meses más tarde, en su intercambio con Orías, Houssay sumaba a esta argumentación una razón crucial: "Aún en los Estados Unidos, las fundaciones particulares están perdiendo terreno y los investigadores cada vez más se fían en recursos del Estado" (Houssay, 1945d).

Sin embargo, esta primavera de normalización tuvo un final abrupto. El papel militante de las universidades como opositoras a la política general del gobierno de facto arrastró nuevamente a las universidades a una situación de enfrentamiento con el poder polí- 
tico-militar. El 19 de septiembre de 1945, tuvo lugar una masiva "Marcha de la Constitución y la Libertad", organizada por sectores universitarios, que finalizó con autoridades universitarias, profesores y estudiantes detenidos. Como contrapunto, el apoyo político a Perón -entonces secretario de Trabajo y Previsión, ministro de Guerra y vicepresidente del gobierno de facto- crecía entre los sectores populares. Iniciado el proceso electoral, el embajador norteamericano Spruille Braden se posicionó como líder político de la oposición. El 9 de octubre, enfrentamientos internos al gobierno provocaron la renuncia de Perón a sus cargos y su posterior encarcelamiento. En una carta al científico brasileño Carlos Chagas, Houssay relataba así este episodio

"Entre los militares hubo un movimiento para suprimir a Perón. Consideraban que el Gobierno no debía emplear todos sus recursos para imponer su candidatura. Ese nuevo Gobierno me invitó a ser Ministro de Justicia e Instrucción Pública diciendo que buscaban elecciones libres y sin presión del Gobierno. Me negué mientras siguiera la dictadura militar [...]".

El 17 de octubre un levantamiento de las clases populares logró la liberación de Perón, ahora firme candidato a la presidencia de la Nación en las elecciones de febrero de 1946. Según Houssay:

"En los días siguientes las reparticiones públicas, Secretaría de Trabajo y Previsión y la Policía y matones pagos interrumpieron el trabajo y provocaron una huelga de trabajadores, 60.000 personas de lo más rotoso y vagabundo que existe, las cuales cometieron excesos en todas las ciudades, protegidos por la Policía. / Se volvió al gobierno anterior y sigue la dictadura y la máquina a favor del nazi Perón [...] (Houssay, 1954e). ${ }^{14}$

Luego de una áspera campaña en la que "el gobierno de los Estados Unidos brindó a Perón un apoyo tan decisivo como involuntario", al publicar, por insistencia de Braden, el llamado Libro Azul, destinado argumentar una supuesta complicidad de Perón con las potencias del Eje, en las elecciones se impuso finalmente Perón con el $56 \%$ de los votos (Rouquié, 1982 [1978], pp. 73). En mayo las universidades fueron intervenidas y al mes siguiente Perón asumió la presidencia. El Poder Ejecutivo promulgó un decreto que dejaba sin efecto los estatutos de las universidades nacionales que fijaban un límite de edad a los profesores titulares para continuar en el ejercicio de la cátedra. A comienzos de septiembre de 1946, el delegado Interventor de la Facultad de Medicina de la UBA dispuso la jubilación de oficio de Houssay, que a su pesar debió retornar al IByME. Como balance de este proceso de enfrentamiento entre un sector de la academia y el poder político, iniciado a mediados de 1943, más de 1200 profesores universitarios fueron dejados cesantes o renunciaron por solidaridad (Frondizi, 1948, pp. 53-54; Ortiz, 1996, p. 173). ${ }^{15}$
La noticia de su jubilación forzada coincidió con un viaje de Houssay a la ciudad de Toronto (Canadá), donde había sido invitado especialmente con motivo de los 25 años del descubrimiento de la insulina, y luego a los Estados Unidos, donde debía pronunciar una serie de conferencias y realizar algunas gestiones vinculadas a las investigaciones de su grupo. "En el Instituto de Fisiología han renunciado gran parte de los ayudantes, jefes de trabajos prácticos y demás personal superior", le informaba Braun Menéndez a Houssay. También agregaba algunos detalles sobre la forma en que se trasladaron gran parte de los renunciantes al IByME: "He tratado de organizar las cosas de tal manera que todos puedan seguir sus experimentos iniciados. Tomé algunas medidas para ampliar la capacidad del Instituto que espero usted aprobará a la vuelta" (Braun Menéndez, 1946a).

Si bien, como se vio, Houssay era conciente de que a nivel internacional los recursos del Estado se tornaban imprescindibles, a partir de este momento, perdidas las esperanzas de recuperar su posición y la de sus discípulos en las universidades públicas, se enfocó en la dirección del IByME, donde ya trabajaban cerca de veinte investigadores. Desde el IByME también comenzó a concebir una nueva estrategia de expansión institucional a partir del presupuesto de la necesidad de consolidar posiciones autónomas del Estado.

\section{EL IBYME, UN “ENSAYO EN PEQUEÑO”}

El enfrentamiento con el gobierno clausuró las posibilidades de la AAPC y del grupo de Houssay de acceder a financiamiento del Estado. De esta forma, en paralelo con la consolidación del IByME, algunos de los científicos de la AAPC vieron una alternativa a esta situación de aislamiento en la creación de una universidad "científica" privada que fuera financiada por filántropos locales. En el imaginario de quienes impulsaron diversas variantes este proyecto, el IByME era concebido como "semilla" para la creación de una universidad privada. ${ }^{16}$

Braun Menéndez estuvo entre los científicos que creyeron que la puesta en marcha de una universidad "científica", al estilo de Stanford o Johns Hopkins, tenía alta probabilidad de desencadenar un flujo de financiamiento proveniente de filántropos locales, produciendo el encuentro entre las "fuerzas vivas del país" y la investigación científica, y que la única vía segura para alcanzar este objetivo consistía "en la creación sucesiva de institutos de investigación científica de acuerdo con un plan preestablecido". Solo estos institutos aseguraban la "investigación desinteresada en temas fundamentales", que era "indispensable para que un país adquiera categoría de nación independiente", en contraposición a los "institutos tecnológicos", que por sí solos "no serían factores reales de 
progreso nacional" (Braun Menéndez, 1945a, pp. 15, 22). El círculo se podría cerrar fuera del Estado si se pudiera persuadir a los empresarios:

"La creación de una universidad libre basada en institutos de investigación debe ser obra de los industriales, los ganaderos, los agricultores, los comerciantes, los viticultores, los cañeros, en una palabra, de las llamadas fuerzas vivas del país. Si estas no despiertan y comprenden que su papel consiste en crear riqueza [...] verán a un estado burocrático absorber poco a poco todas las actividades que legítimamente les corresponden y terminarán por no hacer siquiera dinero, con lo cual desaparecerán como fuerza" (Braun Menéndez, 1945a, p. 24).

En síntesis, los institutos privados de investigación, financiados por una estructura de filantropía privada y enfocados en la realización de investigaciones "fundamentales" y, por lo tanto, "desinteresadas", podían concebirse como un paso intermedio necesario en el camino hacia la "universidad no oficial" con que soñaban algunos científicos argentinos, entre ellos algunos investigadores cercanos a Houssay.

Si bien, durante estos mismos años, como contrapunto de la representación idealizada de la actividad científica que promovía la AAPC, algunos físicos e ingenieros argumentaron a favor de la necesidad de vincular la investigación científica "a la actividad técnico-económica" y criticaron, incluso, "la preocupación quijotesca que impone no propiciar sino esfuerzos desinteresados" (Isnardi, 1943, p. 218), esta posición no significaba estar en contra de la "ciencia pura" o del diagnóstico que concluía que era necesario avanzar en una universidad "científica" no oficial. Por ejemplo, en 1946, el físico Enrique Gaviola -por entonces presidente de la recién creada Asociación Física Argentina y director del Observatorio Nacional de Córdoba-, además de argumentar a favor de la necesidad de crear "laboratorios industriales" e "institutos tecnológicos" y de mostrar interés por los problemas que enfrentaba la industria local, también diagnosticaba que la situación de las universidades oficiales era irreversible, aunque para Gaviola este problema trascendía al actual gobierno y se remontaba a décadas anteriores. ${ }^{17}$ Los problemas que aquejaban a la ciencia argentina eran una mera manifestación de un mal general de decadencia ética. En un escrito titulado $E I$ problema moral argentino y la necesidad de universidades particulares, sostenía: "El mayor prestigio científico y moral de las universidades privadas y de sus egresados obligaría a las oficiales, con el correr de los años, a marcar el paso, como ocurrió en los EE.UU.". Una condición decisiva para que las universidades privadas mantengan su independencia económica, académica y moral, era que fueran "sostenidas por aportes particulares exclusivamente" (Gaviola, 1946, pp. 49-50). Gaviola incluía un apéndice titulado "Sobre la creación de una Universidad Privada" firmado por varios autores, donde la investigación se presentaba como la base del progreso industrial y se planteaban los principios para la creación de un "Instituto-Escuela de Física y de Química". Esta institución funcionaría en base a donaciones y sería el punto de partida de una futura universidad privada: "La creación de la universidad particular argentina será de trascendencia nacional y sudamericana", concluía (Gaviola, 1946, pp. 53-59). ${ }^{18}$

A mediados de 1945, Gaviola y Braun Menéndez habían intentado llevar a delante un proyecto conjunto. Gaviola representaba a los físicos y a un grupo importante de matemáticos y astrónomos que formalmente no integraban la AAPC, mientras que Braun Menéndez representaba al grupo de Houssay y, por lo tanto, a la AAPC. No obstante, luego de algunas reuniones, las discrepancias entre ambos científicos condujeron el proyecto a una vía muerta (Mariscotti, 1985, pp. 4246). Braun Menéndez aclaró poco después el origen de las diferencias en una carta que enviara a Gaviola: "Ud. considera que lo principal y urgente es enseñar; yo que lo principal y urgente es disponer de los medios materiales y espirituales para investigar" (Braun Menéndez, 1945b).

Al margen de estos desacuerdos, los proyectos de crear una universidad "científica" no oficial se tornaron más improbables con la intervención de la Unión Industrial Argentina (UIA). Si bien la UIA había dado la bienvenida a las medidas de protección y estímulo de la industria nacional que había impulsado el gobierno de facto y que ahora el gobierno de Perón proponía profundizar, adoptó una posición crítica con respecto a la tendencia "dirigista" y objetó el carácter compulsivo con que se plantearon las reformas sociales. Bajo la acusación de falta de colaboración y de ausencia de representación de la pequeña y mediana empresa, el peronismo intervino la UIA en mayo de $1946 .{ }^{19} \mathrm{~A}$ pesar de todo, el grupo de Houssay continuó con la idea de crear una universidad privada. En un informe de las actividades del IByME de 1946, puede leerse:

"La idea de organizar una Universidad privada está en el ambiente; estamos convencidos de que está próxima la realización de esa idea y creemos que la mejor solución seria la de ir creando Institutos de investigación científica en los cuales trabajarán intensamente, con dedicación exclusiva, hombres bien elegidos y bien pagados".

Por este motivo, sostenía el informe, el IByME "podrá constituir la base de dicha universidad [...] Este ensayo en pequeño dará la pauta de lo que podrá realizar la reunión de varios institutos constituyendo una universidad privada" (IByME, 1946). Sin embargo, este objetivo era atenuado por la cautela. A comienzos de septiembre de 1947, en un intercambio con Gaviola 
motivado por su jubilación forzada, Houssay le escribía al físico que no deseaba involucrarse en la creación de una universidad privada "mientras no reciba la propuesta de una organización económica segura por un período de 5 o 10 años por lo menos". Mientras esto no ocurra, concluía, "creo que no debo estar propiciando simultáneamente varias instituciones científicas dado lo limitado de los fondos que hasta ahora se dispone para ese fin". Además, argumentaba Houssay, "mi nombre podría representar inconvenientes pues muchas personas temerían que el apoyarme desagradara a los poderes públicos" (Houssay, 1947).

En la revista mensual Ciencia e Investigación, que comenzó a publicar la AAPC desde 1945, el tema de la creación de "universidades libres" fue abordado de forma recurrente. El editorial de enero de 1947, dedicado al tema, se queja de la ley-estatuto para la universidad que se incluye en el Plan Quinquenal proyectado por el gobierno de Perón. "No se constituye una sociedad libre dedicada a la búsqueda desinteresada y a la propagación de conocimientos apoyada y regulada por el Estado". Por el contrario, la institución propuesta "es un instrumento del gobierno" que tampoco respeta la autonomía. El editorial sugiere que: "Para salvaguardar los derechos constitucionales se deberá agregar al proyecto de ley un breve capítulo que de existencia legal a las universidades libres" (Ciencia e Investigación, 1947, pp. 1-2).

En el número de marzo, en la sección "Correspondencia", se publica una carta del físico Gaviola con el título "Las Universidades libres (A propósito de nuestro Editorial de Enero de 1947)". Gaviola se dice sorprendido de haber leído "el editorial sin firma". Y sostiene: "La ley no prohíbe crear universidades libres privadas. No hace falta que lo autorice. Ni en Inglaterra ni en los Estados Unidos existe una ley que autorice la existencia de universidades particulares". En cuanto al temor expresado en el mismo editorial sobre la validez de los títulos expedidos por una universidad privada, Gaviola respondía que la función de éstas es formar hombres de ciencia y no profesionales. "Lo peor que les puede pasar a las universidades privadas es que sean permitidas y reguladas por la ley. Sería la condena a muerte antes de nacer" (Gaviola, 1947). A continuación de la carta de Gaviola se publicó una "Aclaración", que se atribuye la "Mesa de Redacción", en donde se replica que, dado que en nuestro país no existe una tradición de enseñanza libre, "[u]n mínimo de seguridad legal no es mucho exigir para invertir grandes capitales en una empresa, aunque sea de bien público y desinteresada" (Mesa de redacción, 1947).

El último intento del que participó el grupo de Houssay se concretó a mediados de 1953 y tuvo a Braun Menéndez como impulsor. El nuevo proyecto se proponía la creación de un instituto de enseñanza universitaria que pudiera proyectarse como universidad en un futuro no muy lejano. Fue así que aquel año se iniciaron las actividades del llamado "Instituto Católico de Ciencias", destinado a conformar el núcleo de una futura Universidad Católica. ${ }^{20} \mathrm{El}$ editorial de agosto de 1954 de Ciencia e Investigación está dedicado a esta iniciativa. Allí se lee que su nombre no apunta a concebir una ciencia católica contrapuesta a otra que no lo fuera, sino que "se justifica porque es patrocinado por la Jerarquía y contribuyen a sostenerlo católicos" (Ciencia e Investigación, 1953a, p. 338). A pesar del entusiasmo y la dedicación de sus fundadores, el Instituto Católico de Ciencias no reanudó sus actividades en 1955. De acuerdo a un testimonio, cuentan de Asúa y Busala, "fue cerrado por la policía". $Y$ agregan que, si bien el conflicto entre el gobierno y la Iglesia se agudizó a partir de diciembre de 1954, "el ambiente ya estaba suficientemente enrarecido desde unos meses antes" (Asúa y Busala, 2011).

\section{NUEVA ESTRATEGIA DE EXPANSIÓN INSTITUCIONAL}

Cuando, en 1945, se había firmado el decreto de reincorporación de los profesores cesanteados en octubre de 1943, Orías había dejado el IByME para volver con su familia a Córdoba y reintegrarse a la dirección del instituto de la UNC. Sin embargo, a menos de dos años de su reincorporación, junto con sus colaboradores, Orías renunció a este cargo al conocer la noticia de que Houssay había sido jubilado de oficio. ${ }^{21}$ La renuncia de Orías tuvo consecuencias inmediatas. A comienzos de octubre de 1946, Braun Menéndez le escribía a Houssay dándole detalles de la situación: "Me dicen que Orías está muy abatido, sobretodo por la situación que se le ha creado a sus colaboradores y que todavía no ha decidido lo que va a hacer en el futuro" (Braun Menéndez, 1946b).

Ese mismo mes Orías realizó una reunión con un grupo de médicos. Allí se decidió impulsar la organización de un instituto privado de investigaciones médicas en Córdoba bajo la dirección de Orías. ${ }^{22}$ La instalación de los laboratorios comenzó en febrero de 1947. Entre los benefactores más importantes de este período inicial figuraba nuevamente la Fundación Sauberán, pero se sumaban varios miembros de la familia Ferreyra - dueños de una empresa pionera en el desarrollo de la industria de la cal en la provincia de Córdoba-, la Junta Sanitaria de Acción Demócratica y el Jockey Club de Córdoba. Del mismo modo que sucedió en el IByME, recibieron, además de dinero, donaciones en instrumental y en drogas necesarias para realizar sus investigaciones. Además de los aportes de Eduardo Braun Menéndez, Juan Lewis, y algunos otros miembros del IByME, también contaban con un subsidio especial de la AAPC. El nuevo instituto se instalaría en una casa céntrica de la ciudad de Córdoba y contaría con secciones de farmacología química, histología, registro 
óptico de la actividad cardíaca, fotografía y biblioteca (Instituto de Investigación Médica para la Promoción de la Medicina Experimental, 1947, pp. 4-5).

Durante esos primeros días de instalación del nuevo instituto, Orías le enviaba a Houssay una descripción precisa del nuevo instituto. ${ }^{23}$ También le comentaba, con una retórica no exenta de resonancias épicas, la impresión que le había producido la lectura del libro de Simon Flexner sobre William Henry Welch y las memorias de Abraham Flexner:

"Me han hecho ver que el portentoso desarrollo de la Medicina y de la investigación en sus ramas fundamentales no ha surgido en los Estados Unidos por generación espontánea y que el apoyo de los filántropos tampoco vino como un maná celestial; que todo eso se consiguió con esfuerzo, paciencia y sacrificios, luchando contra toda clase de dificultades y también en un ambiente poco propicio. Quiere decir que nuestra situación no es desesperada y que podemos confiar en que nuestros afanes algún día fructificarán" (Orías, 1947).

El 29 de marzo fue realizada la inauguración pública del Instituto de Investigación Médica para la Promoción de la Medicina Científica. Houssay había asistido al acto de inauguración acompañado de un científico de origen sueco, Ulf von Euler, profesor de fisiología en el Instituto Karolinska de Estocolmo, hijo de un premio Nobel de química y él mismo futuro premio Nobel en fisiología o medicina en 1970, que realizaba una estadía de investigación en el IByME desde el año anterior. En su discurso, Houssay sostuvo que "las investigaciones científicas fundamentales se desarrollan en institutos universitarios, industriales o privados, siendo estos últimos los que tienen múltiples ventajas y obtienen los mejores resultados por la libertad con que se trabaja y por la falta de toda traba burocrática" (La Voz del Interior, 1947). En su discurso, Orías recordaba "la tutela científica de Bernardo A. Houssay" y rendía "tributo público de admiración [...] a quienes me cabe el privilegio de poder llamar mis maestros: Bernardo A. Houssay, Carl J. Wiggers y Walter Cannon" (Orías, 1997 [1947]).

Los acontecimientos se aceleraban. Leloir había retornado de los Estados Unidos, donde había estado trabajando en los laboratorios de los esposos Cori, en la Universidad de Washington (Saint Louis, 1944) y con un ex becario norteamericano, D. F. Green, y en el Enzyme Research Laboratory, College of Physicians and Surgeons en la Universidad de Columbia (New York, 1944-1945). Al comienzo se instaló en el Instituto de Fisiología de la UBA. Sin embargo, al poco tiempo de su regreso se había producido la jubilación forzada de Houssay, obligando a Leloir y sus colaboradores a mudarse al IBYME. La precariedad de la situación los había impulsado a trabajar en la creación de un nuevo instituto para albergar al grupo de Leloir. Durante los últimos meses de 1946, Houssay se había reunido con el industrial textil Jaime Campomar, que ofreció el apoyo económico necesario para crear el nuevo instituto. El contacto había sido establecido por el bioquímico Carlos E. Cardini, cuñado de Campomar, que luego se incorporó al IByME a trabajar con Leloir a comienzos de 1947. En esta compleja circunstancia, a pocos meses de haberse inaugurado el instituto de Orías y mientras se avanzaba en la creación de un tercer instituto para el grupo de Leloir, en octubre llegó la noticia de Estocolmo de que Houssay había recibido el premio Nobel de fisiología y medicina.

Con diferente énfasis, los diarios cubrieron el evento. Así, por ejemplo, el diario La Prensa argumentó con detalle sobre la relevancia de la noticia. Como acreedor a la mitad del premio, explicaba, la suma obtenida por Houssay era de 40.580 dólares, mientras que la otra mitad había sido otorgada al matrimonio Cori, a quienes el artículo dedicaba una extensa sección. En este diario también se hablaba de "la escuela de Houssay", se mencionaba a todos los miembros de su grupo y se explicaba en qué consistió el aporte científico que le valió el galardón. Finalmente, se presentaba una trayectoria de su carrera, incluyendo una lista de premios anteriores, así como las vicisitudes por las que había sido dejado cesante en 1943 y más tarde jubilado de oficio (La Prensa, 1947a; b). En las ediciones de los días siguientes este diario cubrió las repercusiones nacionales e internacionales del premio. ${ }^{24}$

El 3 de noviembre de 1947 fue inaugurado el Instituto de Investigaciones Bioquímicas Fundación Campomar como entidad civil sin fines de lucro. Bajo la dirección de Leloir, el instituto inició sus actividades en una casa del barrio de Palermo de Buenos Aires, a la vuelta de la esquina de donde funcionaba el IByME dirigido por Houssay. Los testimonios concuerdan en describir tanto al IByME como al nuevo instituto a cargo de Leloir como lugares precarios para la investigación. ${ }^{25}$

La "Fundación Campomar" dispuso inicialmente para su funcionamiento de una contribución anual de 100.000 pesos (equivalentes a 25.000 dólares de la época), con los que se instaló el laboratorio, se adquirió el equipamiento y se pagaron los sueldos. No fueron ajenos a estos logros los vínculos de Houssay con la Rockefeller Foundation. El instituto de Leloir iba a recibir 1600 dólares de esta fundación en 1950 y 6000 dólares en 1951 para la adquisición de material de laboratorio y equipamiento. También significó un beneficio considerable que el gobierno liberara de impuestos la introducción de materiales donados desde el exterior (Instituto de Investigaciones Bioquímicas, 1951, p. 11).

Simultáneamente a la creación del instituto de Leloir, se iniciaron gestiones para impulsar la creación de un 
cuarto instituto en la ciudad de Rosario. Con esta finalidad, en abril de 1948 fue creada la Asociación Rosarina para el Fomento de la Investigación Científica (ARFIC), bajo la presidencia del médico David Staffieri, fisiólogo que había sido, desde 1940, decano de la Facultad de Medicina de la UNL y, desde 1945, vicerrector. Sin embargo, en marzo de 1946, el gobierno de facto lo había dejado cesante de todos sus cargos. A través de la ARFIC se comenzaron a recaudar fondos por suscripción para la creación de un nuevo instituto. En agosto de 1948 Lewis fue designado para organizarlo y dirigirlo. Finalmente, el 4 de diciembre fue inaugurado el Instituto de Medicina Experimental de Rosario, que fue instalado en una vieja casa en las afueras de la ciudad. En esta ocasión, sostuvo Houssay: "Los institutos privados de investigación tienen la ventaja de su mayor idealismo y mayor libertad en los trabajos, sin trabas burocráticas o influencias políticas, que son tan terriblemente corruptoras y esterilizantes" (Houssay, 1989 [1948], p. 529).

De esta forma, a finales de 1948, Houssay y sus colaboradores más cercanos, no solo habían logrado crear cuatro institutos privados de investigación en las tres ciudades más importantes del país y de esta forma reconstruir una nueva versión del "trípode institucional" desbaratado con el golpe de junio de 1943, sino que además contaban ahora con una AAPC consolidada en sus capacidades - presidida hasta el año siguiente por el propio Houssay-, con la revista mensual Ciencia e Investigación, un premio Nobel y el apoyo de una densa red científica internacional. Como contrapunto, no contaban con el apoyo político ni económico del Estado y en el plano ideológico el enfrentamiento con el gobierno iba creciendo en intensidad.

\section{HOUSSAY VERSUS PERÓN}

Desde los inicios de la primera presidencia de Juan Perón, la actividad científica apareció en el discurso oficial como subsidiaria del desarrollo técnico e industrial. Su representación de la actividad científica, enmarcada en las ideologías desarrollistas dominantes desde la posguerra en muchos países no industrializados, era coherente con la aspiración de profundizar el incipiente proceso de industrialización desde una orientación centralizadora y planificadora de la economía. En términos retóricos, la ciencia y la técnica debían trasformarse en "instrumentos de la felicidad del Pueblo y de la grandeza de la Nación, contribuyendo asimismo al progreso universal" (Presidencia de la Nación, 1953, p. 102). ${ }^{26}$ Algunas universidades, como la Universidad Nacional de Tucumán (UNT) y la Universidad Nacional de Cuyo, se hicieron eco de la consigna de industrialización. Horacio Descole, que actuó como interventor de la primera entre mayo de 1946 y 1948 y como rector entre 1948 y 1951, sostuvo que el desarrollo de "la llamada industria pesada" era uno de los "deberes sagrados" del Primer Plan Quinquenal, que su universidad se disponía a acompañar (Ministerio de Justicia e Instrucción Pública de la Nación, 1947).

La profundidad de la falla política e ideológica que separaba al gobierno de los científicos reunidos en la AAPC y cercanos a Houssay se puso de manifiesto en lo que podría calificarse como un proceso de institucionalización dual de la ciencia en la Argentina. Mientras Houssay y la AAPC impulsaban la creación de institutos privados guiados por valores como la libertad de investigación, la autonomía política del Estado (o autorregulación de sus actividades), la promoción de estándares internacionales y la ciencia pura o fundamental como principal objetivo, el gobierno de Perón impulsó un modelo de ciencia integrado a la planificación económica y a los "problemas nacionales" energía, salud, recursos naturales, producción, defensa-. Esta orientación se materializó en una política de salud pública centrada en la creación y mejora de hospitales y el combate de las enfermedades endémicas, y en la creación de instituciones como la Comisión Nacional de Energía Atómica (1950), la Dirección Nacional de Investigaciones Técnicas, dependiente del Ministerio de Asuntos Técnicos (1950) - que poco más tarde pasó a llamarse Dirección Nacional de Investigaciones Científicas y Técnicas-, institución central en los planes de organización y coordinación del área de ciencia y técnica, o el Instituto Antártico Argentino (1951), que vinculó la ciencia al reclamo de soberanía sobre un sector de la Antártida. ${ }^{27}$

En este escenario escindido por el enfrentamiento de dos representaciones divergentes que combatían por la legitimidad de la producción científica y por la definición de su función social, Houssay difundió en el exterior una valoración negativa de los emprendimientos oficiales relativos al área de las ciencias biomédicas, asoció las iniciativas del gobierno a lo que ocurría en los estados totalitarios y caracterizó al propio Perón con atributos como "coronel mitómano" o "nazi". ${ }^{28}$ En su carácter de corresponsal en Buenos Aires de la sección "Foreign Letters" del Journal of the American Medical Association (JAMA), Houssay le informó a su editor que, si bien el ministro de Salud Pública Ramón Carrillo había inaugurado, en octubre de 1949, un Instituto Central de Cardiología, el más importante centro de investigación en esta área continuaba siendo el Centro de Investigaciones Cardiológicas de la Universidad de Buenos Aires, bajo la dirección de Alberto C. Taquini. ${ }^{29} \mathrm{Y}$ agregaba Houssay:

"En los últimos años, el Ministerio de Salud Pública ha creado muchos nuevos institutos de diferentes clases, que ahora alcanzan a 40 direcciones y 34 institutos. Algunos de ellos tienen denominaciones inusuales tales como Instituto Pro-vida, Instituto de la Población, Instituto de Clínica Tecnológica, etc" (Houssay, 1949). ${ }^{30}$ 
Como parte del intercambio epistolar periódico que mantuvo con Morris Fishbein -editor del JAMA entre 1924 y $1950-$, Houssay le contará que:

"[...] la única organización médica verdadera de nuestro país es la Asociación Médica Argentina, de la cual ustedes reciben la revista. Es importante para la American Medical Association estar familiarizados con esta asociación y no con organizaciones formadas por razones políticas" (Houssay, 1951).

También la revista Ciencia e Investigación fue utilizada para criticar los intentos de planificar la ciencia, de "subordinarla al estado". Tomando ejemplos de los estados totalitarios, oponiéndose a los enfoques utilitaristas y reafirmando la necesidad de autonomía como condición imprescindible, se buscaba poner de relieve "las consecuencias nefastas" de la excesiva intromisión del estado. Si bien Ciencia e Investigación se caracterizó por la cautela política, algunos editoriales avanzaron sobre la crítica frontal. El editorial de Ciencia e Investigación de diciembre de 1953 apuntaba contra el Segundo Plan Quinquenal del gobierno. El editorial reclamaba "un ambiente de libertad", señalaba el peligro de obtener "resultados contraproducentes" si se aplicaba "un criterio estrechamente utilitario". Lo que guiaba la política científica del gobierno era el mayor error, según los editores de Ciencia e Investigación: "La confusión proviene de que no se hace distingo entre ciencia y técnica, deficiencia que se observa en todo el plan donde trata de la investigación" (Ciencia e Investigación, 1953b).

Frente a estas manifestaciones de oposición, el gobierno, a medida que fue articulando una representación del campo científico más elaborada que reforzaba sus objetivos políticos, fue construyendo una posición de "outsiders" para los científicos opositores. En las palabras del propio Perón:

“[...] el progreso científico podrá darnos máquinas más eficaces y seguras; alimentos más sanos, nutritivos y económicos; casas más higiénicas, cómodas y asequibles. Podrá encontrar los medios de conservar la salud, de preservarnos de las enfermedades y curarnos mejor; podrá poner a nuestro alcance, generalizándolos, medios más eficaces para distracción del alma y preparación de nuestras energías físicas y morales" (citado en: Universidad, 1952, p. 387).

En este contexto, se respondía a los científicos que no se comprometían con este proyecto y, como corolario, se concluía la necesidad del acceso de los hijos de la clase trabajadora al mundo de la ciencia y de la técnica:

"La revolución justicialista, al arrebatar el monopolio del patrimonio científico de las manos rapaces de un reducido grupo social, inyecta nueva vida y nueva sangre a la actividad científica aspirando - mediante el acceso de los hijos de obreros a la enseñanza superior - a la renovación constante y fecunda de los cuadros de investigadores y técnicos" (citado en: Universidad, 1952, p. 390).

También el Segundo Plan Quinquenal, puesto en marcha en 1953, se refería a "la resistencia de tantos seudoinvestigadores técnicos y científicos, firmantes de tantos manifiestos políticos en nombre de la ciencia" y al sector de científicos que "prefirió seguir al servicio del imperialismo" (Presidencia de la Nación, 1953 , p. 111). Finalmente, la revista trimestral de divulgación científica Mundo Atómico, que se comenzó a publicar en 1950, tuvo un lugar central en esta disputa, como canal de difusión (y también espacio de elaboración) de la representación oficial. En sus páginas se pone en evidencia el esfuerzo por construir una representación donde la ciencia y la técnica aparezcan asimiladas al proceso de planificación económica y como componentes primarios en el proceso de construcción de la "Nueva Argentina". ${ }^{11}$

Para 1954, la activa oposición de Houssay al gobierno de Perón se había vuelto más frontal. El 26 de octubre, en la conferencia leída por Houssay en el Simposio "Responsible Freedom in the Americas", que tuvo lugar en la Universidad de Columbia para conmemorar su segundo centenario de existencia, Houssay desarrolló lo que puede ser su expresión epistemológica, académica y política más clara e integrada de la que haya quedado testimonio. Houssay argumentaba: "Los principales factores del lento desarrollo de la ciencia en América Latina pueden agruparse en: 1ㅇ) ignorancia; 2의) vanidad; 3 의) defectos técnicos; 4으) defectos intelectuales; 5) defectos morales; 6ㅇ) fallas de carácter y personalidad". También presentaba allí su representación del proceso de producción de conocimiento en tres etapas. "Primero, un investigador aislado e independiente hace un descubrimiento importante, por una inspiración individual y original, que solo nace en un ambiente de libertad y respeto a la ciencia". Luego "se desarrollo, perfecciona y amplía el descubrimiento por obra de numerosas investigaciones especializadas". Y finalmente, "se coordina la producción industrial y su aplicación social". Esta construcción, que hoy asociaríamos al Ilamado "modelo lineal", le permitía concluir: "Sin investigación científica fundamental (o pura), una Universidad o un país están condenados a la inferioridad. Prohibirla es una especie de suicidio nacional" (Houssay, (1989) [1954], p. 334).

En cuanto a los valores y criterios que justificaban las agendas de investigación, Houssay adoptaba una visión internacionalista sin matices, que vinculaba la actividad científica a los valores éticos y democráticos que desde una perspectiva liberal aparecían como los más elevados. En síntesis, la ciencia "es un producto de la colaboración internacional", "un factor de cultura" y "condición de libertad". Como contraposición, 
sostenía Houssay, existe una posición extrema que "lleva a considerar que a los hombres de ciencia no puede dárseles la libertad de elegir el objeto de sus investigaciones; éstas deben ser dirigidas y planificadas". Y concluía: "Así, S. I. Vavilov ha dicho que "los días de la llamada ciencia pura han terminado para siempre en el país de los Soviets', expresión que ha sido imitada por algunos gobernantes sudamericanos" (Houssay, (1989) [1954], pp. 329-330). ${ }^{32}$

\section{EPÍLOGO CON NUEVO GOLPE MILITAR}

En septiembre de 1955 un golpe de Estado ponía fin a poco más de nueve años de democracia y Perón partía al exilio. El editorial de Ciencia e Investigación inmediatamente posterior a estos sucesos sostenía: "Nuestra revista, que nació en 1945, pudo sobrevivir la época más desfavorable que haya tenido nuestra historia para el progreso científico". Y proponía más abajo: "Durante 10 años se ha edificado un andamiaje de falsa ciencia que es preciso desmontar" (Ciencia e Investigación, 1955). Esta afirmación estaba a tono con el antiperonismo visceral que orientó el intento de reorganización de las instituciones a escala nacional impulsada por la nueva dictadura, que caracterizaba a un gobierno elegido por los votos como "dictadura totalitaria". En este momento se inicia un período que llega hasta comienzos de la década de 1970, en el cual el rasgo dominante de la vida política del país sería la proscripción del peronismo y, como consecuencia de la exclusión del sector político mayoritario, el predominio de una lógica corporativa de distribución de los espacios de poder modulada por la oscilación entre gobiernos autoritarios y "semidemocráticos". 33 La organización del complejo institucional de ciencia y tecnología padecería esta impronta y la figura de Houssay, por esos años icono del antiperonismo científico, lideraría la consolidación de este proceso en el ámbito de la ciencia académica.

Con la expulsión de Perón, Houssay fue reincorporado como director del Instituto de Fisiología de la UBA. Sin embargo, en 1956 renunció a este cargo para dedicarse exclusivamente al IByME. Si bien Lewis había dejado su instituto en 1954 como consecuencia de habérsele diagnosticado la enfermedad de Parkinson y Orías había fallecido inesperadamente a comienzos de junio del año siguiente, los cuatro institutos privados del grupo de Houssay durante los años siguientes se integraron, por diversos caminos, al complejo público de investigación. ${ }^{34}$

La DNICyT creada durante el gobierno de Perón fue intervenida. Luego de un proceso de consulta, que incluyó una encuesta a científicos y profesores universitarios sobre las necesidades del sistema científico, el vicepresidente de facto, almirante Isaac Rojas -representante de la "línea dura" contra el peronis- mo-, se reunió con una delegación de la Academia Nacional de Ciencias Exactas, Físicas y Naturales. Allí se acordó la presentación de una propuesta de organización de un consejo nacional de investigaciones. A los pocos días, una comisión especial, integrada por Bernardo Houssay, Eduardo Braun Menéndez, los químicos Venancio Deulofeu -desde 1949 presidente de la AAPC - y Abel Sánchez Díaz, y el físico Ernesto Galloni, entregó al Poder Ejecutivo un anteproyecto de decreto en junio de 1957. Esta iniciativa incluía la supresión de la DNICYT, creada por el gobierno de Perón, y el paso de sus bienes y personal administrativo al nuevo organismo. Este proceso derivó en la creación, en febrero de 1958, del Consejo Nacional de Investigaciones Científicas y Técnicas (CONICET), como ente autárquico dependiente directamente del Poder Ejecutivo. Houssay sería su primer presidente hasta el día de su muerte el 21 de septiembre de 1971.

En términos generales, el enfrentamiento entre el grupo de Houssay y el gobierno de Perón puede concebirse como una "proyección periférica" de la disputa que, en el escenario mayor de los países industrializados y la guerra fría, tuvieron manifestaciones tales como la confrontación de las posiciones de Michael Polanyi y John Bernal o, más concretamente en el caso particular de los Estados Unidos, en el enfrentamiento durante la segunda mitad de los años cuarenta de los proyectos de Vannevar Bush y del senador demócrata Harley Kilgore. Mientras que Bush, a través de su célebre informe Science-the Endless Frontier, ponía en un lugar de preeminencia a la investigación básica - aquella que es "realizada sin pensar en fines prácticos", como contribución "al conocimiento general y a la comprensión de la naturaleza y sus leyes" - y reclamaba que los científicos debían decidir por sí mismos cómo emplear los fondos federales (Bush, 1945, p. $18)$, Kilgore elevaba un proyecto de ley donde se proponía un control democrático directo sobre los fondos federales que deberían distribuirse de acuerdo a criterios fijados por un consejo de representantes de todos los sectores sociales relevantes, incluidos los consumidores y los pequeños empresarios. Una versión muy difundida de este enfrentamiento sostiene que, en términos formales, en los Estados Unidos se impuso la posición, asociada a Bush, que algunos autores caracterizaron más tarde con la metáfora del "contrato social para la ciencia". ${ }^{35}$ Un producto de este proceso fue la creación, en 1950, de la National Science Foundation -el organismo concebido para impulsar la investigación básica-, institución presentada como la evidencia más visible y concluyente de la victoria de la posición de Bush. Sin embargo, en los hechos, durante 1955, por ejemplo, cuatro quintos del presupuesto federal para investigación y desarrollo eran destinados en los Estados Unidos al Departamento de Defensa (Dickson, 1988, pp. 25-27). En una reedición del "informe Vannevar Bush" que conmemoraba los 
diez años de creación de la National Science Foundation, su entonces presidente Alan Waterman sostenía en la introducción que el foco central de Bush era la importancia de la investigación básica, aunque el balance era diferente a lo que se deduciría de la retórica: "Sin embargo, el incremento del porcentaje de fondos disponibles para ciencia básica ha fracasado en relación al total de fondos federales para investigación y desarrollo - permaneciendo entre el 6 y el $7 \%$ a lo largo de los años" (Waterman, 1960, p. ix). Incluso, según el historiador ruso Kojevnikov, con el lanzamiento del Sputnik "la expresión 'ciencia pura' murió gradualmente en el vocabulario de los científicos norteamericanos" (Kojevnikov, 2008, p. 133).

Cuando en los países avanzados se desplegaba esta orientación decidida hacia el empleo de la ciencia y la tecnología como motores de desarrollo económico y militar, la ausencia de políticas públicas para este sector durante el gobierno de facto que había derrocado a Perón, a fines de los años cincuenta, allanó el camino para que el grupo de científicos reunidos alrededor de Houssay imprimiera al CONICET y a buena parte de las actividades de investigación en las universidades la impronta de la libertad de investigación, la autorregulación de la actividad científica - aunque ahora combinada con el financiamiento del Estado- y la ciencia básica como el objetivo fundamental. Es así como el enfrentamiento peronismo-antiperonismo también instaló una profunda falla entre la ciencia académica y el impulso de otras áreas de investigación y desarrollo, como, por ejemplo, el sector nuclear. Iniciado durante el gobierno de Perón, después de su derrocamiento el área nuclear logró preservar la ideología que estuvo en sus orígenes, definida por la búsqueda de la autonomía tecnológica - entendida como la capacidad del país para alcanzar objetivos tecnológicos sin interferencias o restricciones externas - y el impulso del proceso de industrialización y del liderazgo científicotecnológico regional, por momentos conceptualizado como parte del proyecto de integración regional, por momentos desde los intereses comerciales proyectados sobre la potencialidad de un mercado nuclear regional. Este proyecto, que dio preeminencia a la tecnología y que tuvo como enclave institucional a la Co- misión Nacional de Energía Atómica, era inconciliable con la ideología institucional del grupo de científicos que lideró el CONICET. ${ }^{36}$

Esta dualidad de representaciones iba a persistir en las décadas siguientes y su manifestación más evidente iba a ser un proceso de institucionalización fragmentado. Por un lado, una ciencia académica capaz de lograr reconocimiento internacional, pero desconectada de las necesidades sociales y económicas. Por otro lado, instituciones creadas al margen del tándem universidades-CONICET, dedicadas al desarrollo de tecnologías para la industria, el agro, la energía atómica, las Fuerzas Armadas o los recursos naturales. Los intentos de comprender esta fragmentación desde fines de los años sesenta iban a mostrar sus profundos vínculos con los procesos de dependencia económica y cultural de América Latina. ${ }^{37}$

\section{ABREVIATURAS}

AAPC: Asociación Argentina para el Progreso de las Ciencias.

ARFIC: Asociación Rosarina para el Fomento de la Investigación Científica.

CONICET: Consejo Nacional de Investigaciones Científicas y Técnicas.

DNICYT: Dirección Nacional de Investigaciones Científicas y Técnicas.

IByME: Instituto de Biología y Medicina Experimental.

AMBH: Museo Archivo Bernardo Houssay.

UBA: Universidad de Buenos Aires.

UNL: Universidad Nacional del Litoral.

\section{AGRADECIMIENTOS}

Los autores desean dedicar este trabajo a la memoria de Alfonso Buch. 


\section{NOTAS}

1 A modo de ejemplo, puede verse: Houssay (1934; 1939); Lewis (1934); AAPC (1935).

2 La Ley 12.338 fue sancionada por el Congreso el 21 de diciembre de 1936 y reglamentada por el Poder Ejecutivo un año más tarde.

3 Sobre orientación política del golpe de 1943, puede verse: Zanatta (2009, pp. 44-45).

4 Un tratamiento exhaustivo de los vínculos de Houssay con la Fundación Rockefeller puede verse en: Cueto (1994).

5 Puede verse también: New York Times (1943).

6 Entre 1935 y 1946 fueron concedidas 40 becas externas originadas en la Ley 12.338 ( 12 a médicos, 12 a ingenieros, 8 a químicos y bioquímicos), y entre 1937 y 1940 se distribuyeron 6 becas donadas por los Laboratorios Millet y Roux, todas a médicos. De las alrededor de 45 becas internas otorgadas entre 1933 y 1945 , el $60 \%$ fueron otorgadas a médicos. En cuanto a subsidios, de 87 otorgados en el mismo período, un $30 \%$ fueron a médicos y otro $30 \%$ a químicos y bioquímicos. AAPC (s/f, pp. 3-6).

7 Sauberán falleció en 1938.

8 El padre del abogado era un médico francés radicado en Buenos Aires que había sido amigo cercano de Houssay. Un informe detallado sobre la "Donación Sauberán" original puede verse en: AAPC (1937).

9 Una crónica familiar de los antepasados de Braun Menéndez puede verse en: Braun (1985).

10 Luis F. Leloir había viajado ese mismo año a Estados Unidos, pero a su regreso se integraría al grupo.

11 En esta breve nota se comenta también el apoyo de la Rockefeller Foundation.

$12 \mathrm{Al}$ año 1946, el comité del Houssay Journal Fund había recibido 247 donaciones, que sumaban poco más de 1500 dólares, con lo que Houssay pudo pagar cinco años de suscripciones de 18 revistas (Houssay, 1946).

13 Los fondos se distribuían entre: gastos de alquiler, gastos generales, sueldos, comida para los animales, instrumental, drogas, construcciones y material de biblioteca (Houssay, 1946).

14 Un relato detallado de los episodios que convergen en el levantamiento popular del 17 de octubre de 1945, puede verse en: Rouquié (1982 [1978], pp. 63-72).

15 También puede verse: Mangone y Warley (1984, pp. 24-40).

16 A modo de ejemplo, puede citarse al ingeniero Augusto Durelli, a quien la AAPC le había otorgado en 1939 una beca para hacer estudios de perfeccionamiento en fotoelasticidad en el Massachusetts Institute of Technology. Para Durelli, el IByME era candidato a convertirse un día no muy lejano en una universidad como Harvard, Princeton u Oxford (Durelli, 1947, p. 54).

17 Gaviola, al igual que otros físicos como Guido Beck, no eran miembros de la AAPC, si bien mantenían relaciones de colaboración con el grupo de Houssay.
18 Los firmantes de esta segunda parte eran el propio Gaviola, además de Ernesto Galloni, Juan Batana y Rodolfo Busch.

19 La UIA permaneció en esta situación hasta 1953, año en que fue disuelta, para volver a recobrar su personería jurídica luego del derrocamiento de Perón, a fines de 1955 (Schvarzer, 1991, pp. 83-113).

20 Con sede en Buenos Aires, el edificio había sido cedido por entonces director de los Cursos de Cultura Católica, Cgo. Luis M. Etcheverry Boneo (Iatria, 1953, p. 148).

21 Sobre la trayectoria de Orías, puede verse: Houssay (1989 [1956]); Buch (2002, pp. 384-403).

22 Participaron de la reunión Severo Amuchástegui, Agustín Caeiro, Enrique Moisset de Espanés, Calixto Nuñez.

23 "Como locales contamos con 6 habitaciones de piso de mosaico, de aproximadamente $5 \times 5 \mathrm{~m}$., tres de ellas con pileta, agua corriente y murales de cemento armado recubiertas por mosaicos. Una de ellas se destinará a biblioteca otra a escritorio y las demás serán laboratorios. Hay además un garage para fotografía, dos patios amplios, un galpón con techos y pared en tres costados para perros y otro galponcito con cuatro paredes y techo donde instaremos el criadero de ratas. Todo esto además de baños cuarto para la casera y cocina" (Orías, 1947)

24 Puede verse: La Prensa (1947c; d; e).

25 Ver, por ejemplo: Carminatti (2006); Belocopitow (1992, p. 61).

26 Sobre desarrollismo, centralización y planificación del gobierno de Perón, puede verse: Berrotarán (2004); Elena (2006).

27 Si bien se trata de una temática escasamente abordada, para una visión panorámica sobre las instituciones científicas impulsadas durante el gobierno de Perón, puede verse: Hurtado y Busala (2006). Sobre la política de salud pública durante este período, puede verse: Ramacciotti (2009)

28 Ver, por ejemplo: Houssay (1945d).

29 El Centro de Investigaciones Cardiológicas al que se refiere Houssay había sido inaugurado en 1944 en un edificio donado por la Fundación Virginio Grego y equipado con instrumental cedido por la Rockefeller Foundation. Ver: Taquini (1981, p. 174); Barrios Medina (2002, p. 515).

30 En inglés en el original. Smith fue editor de JAMA entre 1949 y 1958. La opinión negativa que Houssay tenía del secretario y luego ministro de Salud Pública del peronismo entre 1946 y 1954 puede retrotraerse a fines 1945 , cuando la situación política en la Facultad de Ciencias Médicas de la Universidad de Buenos Aires, donde era decano interino Ramón Carrillo, nuevamente se tornaba adversa. Entonces Houssay escribía: "La situación universitaria tiene aspectos entre cómicos y trágicos. Carrillo es un caballo de Troya puesto para que el peronismo pueda invadir las universidades y desarmar ese foco de oposición tenaz que le molesta grandemente" (Houssay, 1945d).

31 Para un estudio detallado de esta publicación, puede verse: Hurtado y Feld (2010); Del Valle Marzoratti (2012, pp. 78-102 y 127-144). 
32 Con referencia a la repercusión de la conferencia de Houssay, puede verse: Bracker (1954).

33 Sobre el concepto de "semidemocracia", ver: Cavarozzi (2006, pp. 15-35).

$34 \mathrm{Si}$ bien el Instituto de Investigaciones Bioquímicas conservó su estatus jurídico de instituto privado, su futura articulación con otras instituciones centrales del complejo de ciencia y tecnología como el Consejo Nacional de Investigaciones Científicas y Técnicas (CONICET) y la Facultad de Ciencias Exactas y Naturales de la UBA hablan de un alto grado de integración con el complejo público de ciencia. Detalles sobre este punto pueden verse en: Parodi (2006, p. 30).

35 Brooks explica: "El contrato social prometió la difusión de amplios beneficios a la sociedad y a la economía a cambio de acordar un inusual grado de autonomía intelectual y autogobierno interno por parte de los receptores del apoyo federal". Es decir,

\section{BIBLIOGRAFÍA}

AAPC (1935), Primer informe sobre el estado actual de las ciencias en la Argentina y sus necesidades más urgentes (folleto), Buenos Aires, Establecimientos Gráficos "Tomás Palumbo".

AAPC (1937), Fundación Sauberán para el Fomento de las Investigaciones en Fisiología (folleto), Buenos Aires, Librería y Casa Editora de A. Guidi Buffarini.

AAPC (s/f), Memoria y balance del 23 ejercicio 1955-1956 (folleto), Buenos Aires, Compañía Impresora Argentina S.A.

Asúa, Miguel de y Busala, Analía (2011), "Instituto Católico de Ciencias (1953-1954). Más en la leyenda que en la historia", Criterio, (2368). Disponible en: http://www.revistacriterio.com.ar/cultura/instituto-catolico-de-ciencias-1953-1954-mas-en-la-leyendaque-en-la-historia/ [consultado el 14/8/2010]

Barrios Medina, Ariel (2002), "Ciencias Biomédicas", En: De Marco, M. (coord.), Nueva Historia de la Nación Argentina, Tomo IX, Buenos Aires, Planeta. pp. 501-523.

Bracker, Milton (1954), "Freedom to Teach Seen in Dire Peril", New York Times, 27 de octubre, p. 15.

Braun, Mauricio (1985), Memorias de una vida colmada, Buenos Aires, Gaglianone Establecimiento Gráfico S.A.

Braun Menéndez, Eduardo (1945a), Universidades no oficiales e institutos privados de investigación científica (folleto), Buenos Aires, s/e.

Braun Menéndez, Eduardo (1945b), Carta a Gaviola, Buenos Aires, 8 de octubre, Biblioteca del Centro Atómico Bariloche, Archivo Gaviola.

Braun Menéndez, Eduardo (1946a), Carta a Houssay, Buenos Aires, 14 de septiembre, AMBH 08 (11- 186-26).

Braun Menéndez, Eduardo (1946b), Carta a Houssay, Buenos Aires, 1 de octubre, AMBH 08/11/1884. una relación con el Estado que debía garantizar autonomía, financiamiento y las condiciones institucionales indispensables para las actividades de investigación básica que la revisión por pares decidiera como relevante. A cambio, los científicos realizarían sus investigaciones de manera honesta, asegurando resultados que tarde o temprano encontrarían aplicaciones en la industria, el agro, la medicina o la defensa (Brooks, 1990, p. 12). Una discusión del llamado "contrato social para la ciencia" puede verse en: Guston y Keniston (1994).

36 Sobre la creación del CONICET y sus primeros años de trayectoria, puede verse: Hurtado (2010, pp. 106-115). Sobre los primeros años del desarrollo nuclear en la Argentina, puede verse: Hurtado (2005).

37 Dos obras representativas de este momento son Varsavsky (1969) y Herrera (1971).

Belocopitow, Enrique (1992), Instituto Luis F. Lelor; Fundación Campomar: qué es, qué hace y qué produce, Buenos Aires, s/e.

Berrotarán, Patricia (2004), "La planificación como instrumento: políticas y organización en el estado peronista (1946-1949)", En: Berrotarán, P.; Jáuregui, A.; Rougier, M. (eds.), Sueños de bienestar en la Argentina. Estado y políticas públicas durante el peronismo, 1946/1955, Buenos Aires, Imago Mundi. pp. 15-45.

Brooks, Harvey (1990), "Lessons of history: Successive challenges to science policy", En: Cozzens, S., Healey, P., Rip, A. y Ziman, J. (eds.), The research system in transition, Boston, Kluwer Academic Publishers. pp. 11-22.

Buch, Alfonso (2002), Forma y función de un sujeto moderno. Bernardo Houssay y la fisiología argentina (1900-1943), Bernal, Editorial de la Universidad Nacional Quilmes.

Bush, Vannevar (1945), Science-The Endless Frontier: A Report to the President on a Program for Postwar Scientific Research, Washington, National Science Foundation.

Carminatti, Héctor (2006), "Luis Federico Leloir, cien años después", La Nación, 5 de septiembre, p. 14.

Cavarozzi, Marcelo (2006), Autoritarismo y democracia (19552006), Buenos Aires, Ariel.

Ciencia e Investigación (1947), "Las universidades libres" (Editorial), 3, pp. 1-2.

Ciencia e Investigación (1953a), "El Instituto Católico de Ciencias", 9, pp. 337-338.

Ciencia e Investigación (1953b), “Editorial”, 9, pp. 529-531.

Ciencia e Investigación (1955), "La ciencia necesita un ambiente de libertad” (Editorial), 11, pp. 433-434.

Cortesi, Arnaldo (1943), "Argentina Widens 'Communist' Hunt", New York Times, 3 de diciembre, p. 15. 
Cueto, Marcos (1994), "The Rockefeller Foundation's Medical Policy and Scientific Research in Latin America", En Cueto, M. (ed.), Missionaries of Science: The Rockefeller Foundation and Latin America, Bloomington, Indiana University Press. pp. 126-148.

Del Valle Marzoratti, Zulema (2012), Plantear utopías. La conformación del campo científico-tecnológico nuclear en la Argentina (1950-1955), Buenos Aires, Ciccus-Clacso.

Dickson, David (1988), The New Policy of Science, Chicago, The University of Chicago Press.

Durelli, Augusto (1947), Del universo de la universidad al universo del hombre, Buenos Aires, Talleres gráficos "Tomás Palumbo".

Elena, Eduardo (2006), "The Promise of Planning: Technocracy and Populism in the Making of Peronist Argentina", En: García Sebastiani, M. (ed.), Fascismo y antifascismo, peronismo y antiperonismo, Madrid, Iberoamericana. pp. 133-160.

Firmantes del manifiesto (1945), Por qué no nos reincorporamos (folleto), Buenos Aires, Talleres Gráficos de Emilio Bustos.

Frondizi, Risieri (1948), “Las Universidades Argentinas bajo el Régimen de Perón", Cuadernos Americanos, 38 (2), pp. 40-60.

Gaviola, Enrique (1946), El problema moral argentino y la necesidad de universidades particulares (folleto), Buenos Aires, s/e.

Gaviola, Enrique (1947), "Las Universidades libres (A propósito de nuestro Editorial de Enero de 1947)", Ciencia e Investigación, 3 , pp. 129-130.

Guston, David y Keniston, Kenneth (1994), "Introduction: The Social Contract for Science”, En: Guston, D. y Keniston, K. (eds.), The Fragile Contract. University Science and the Federal Government, Cambridge (Mass.), The MIT Press. pp. 1-41.

Hall Sharp, Ronald (1945), "Door Opening to Argentina: U.S. Tries New Strategies?". Christian Science Monitor, 29 de marzo, pp. 1, 8.

Herrera, Amilcar (1971), Ciencia y política en América Latina, México, D.F., Siglo XXI.

Houssay, Bernardo (1934), La ayuda a la ciencia en Bélgica (folleto), Buenos Aires, Librería y Casa Editoria de A. Guidi Buffarini.

Houssay, Bernardo (1939), El problema de las becas de perfeccionamiento (folleto), Buenos Aires, Establecimientos Gráficos "Tomás Palumbo".

Houssay, Bernardo (1944), Carta a L. Dexter, Buenos Aires, 9 de marzo, AMBH, 08-6/2318.

Houssay, Bernardo (1945a), Borrador Informe del IByME, AMBH, 08-11-103-37.

Houssay, Bernardo (1945b), Carta a Leloir, Buenos Aires, 7 de junio, AMBH 08/6/4433.

Houssay, Bernardo (1945c), Carta a Oscar Orías, Buenos Aires, 18 de julio, AMBH 08-6/9032.

Houssay, Bernardo (1945d), Carta a Oscar Orías, Buenos Aires, 14 de noviembre, AMBH 08-6/9063.
Houssay, Bernardo (1945e), Carta a Carlos Chagas, Buenos Aires, 29 de octubre, AMBH 08-6/1644.

Houssay, Bernardo (1946), Borrador Informe del IByME, AMBH 08$11-1680 / 04$.

Houssay, Bernardo (1947), Carta a Enrique Gaviola, Buenos Aires, 2 de septiembre, Archivo Gaviola, Biblioteca del Centro Atómico Bariloche.

Houssay, Bernardo (1949), Carta a Austin Smith, Buenos Aires, 19 de septiembre, AMBH 08-6/364.

Houssay, Bernardo (1951), Carta a Morris Fishbein, Buenos Aires, 19 de mayo, AMBH 08-6/387.

Houssay, Bernardo (1959), "Vida y obra científica de Eduardo Braun Menéndez (1903-1959)", Ciencia e Investigación, 15 (4-5), pp. 97-104.

Houssay, Bernardo (1964), "Pasado y futuro de la Asociación Argentina para el Progreso de las Ciencias y su papel en el adelanto de la Argentina", Ciencia e Investigación, 20 (2), pp. 82-86.

Houssay, Bernardo (1989) [1945], "Primera Memoria del Instituto de Biología y Medicina Experimental", En: Barrios Medina, A. y Paladini, A. (comps.), Escritos y Discursos del Dr. Bernardo A. Houssay, Buenos Aires, Amorrortu. pp. 175-191.

Houssay, Bernardo (1989) [1948], “Discurso en la inauguración del Instituto de Investigaciones Médicas de la Asociación Rosarina para el Fomento de las Ciencias", En: Barrios Medina, A. y Paladini, A. (comps.), Escritos y Discursos del Dr. Bernardo A. Houssay, Buenos Aires, Amorrortu. pp. 528-530.

Houssay, Bernardo (1989) [1954], "La libertad académica y la investigación científica en la América Latina", En: Barrios Medina, A. y Paladini, A. (comps.), Escritos y Discursos del Dr. Bernardo A. Houssay, Buenos Aires, Amorrortu. pp. 328-347.

Houssay, Bernardo (1989) [1956], "La vida ejemplar de Oscar Orías", En: Barrios Medina, A. y Paladini, A. (comps.), Escritos y Discursos del Dr. Bernardo A. Houssay, Buenos Aires, Amorrortu. pp. 490-498.

Houssay, Bernardo (s/f), Nota manuscrita, AMBH, 08-11/1012.

Hurtado (2005), "Autonomy, even regional hegemony: Argentina and the 'hard way' toward the first research reactor (19451958)", Science in Context, 18 (2), pp. 285-308

Hurtado, Diego y Busala, Analía (2006), “De la 'movilización industrial' a la 'Argentina científica': la organización de la ciencia durante el peronismo (1946-1955)", Revista da Sociedade Brasileira de História da Ciência, 4 (1), pp. 17-33.

Hurtado, Diego y Feld, Adriana (2010), "La revista Mundo Atómico y la 'Nueva Argentina' científica (1950-1955)", En: Panella, C. y Korn, G. (eds.), Ideas y debates para la Nueva Argentina. Revistas culturales y políticas del peronismo (1946-1955), La Plata, Edulp. pp. 199-228.

Hurtado, Diego (2010), La ciencia argentina. Un proyecto inconcluso (1930-2000), Buenos Aires, Edhasa. 
Iatria (1953), “El 'Instituto Católico de Ciencias'”, 24, pp. 147-150.

IByME (1946), "Informe IByME", Buenos Aires, s/e, AMBH 08-114390.

Instituto de Investigaciones Bioquímicas (1951), Memoria del Instituto de Investigaciones Bioquímicas "Fundación Campomar", 1947-1951, Buenos Aires, s/e.

Instituto de Investigación Médica para la Promoción de la Medicina Experimental (1947), Primer informe anual, Córdoba, s/e.

Isnardi, Teófilo (1943), "La investigación científica. La universidad y la industria en nuestro país", Revista de la Universidad de Buenos Aires, tercera época, 1 (2), pp. 213-236.

Kojevnikov, Alexei (2008), "The Phenomenon of Soviet Science", Osiris, 23, pp. 115-125.

La Prensa (1947a), "Bernardo A. Houssay y Carlos F. Cori y su Esposa Obtienen el Premio Nobel", 24 de octubre, p. 7.

La Prensa (1947b), "Bernardo A. Houssay y Carlos F. Cori y su Esposa Obtuvieron el Premio Nobel de Medicina", 24 de octubre, pp. 9-10.

La Prensa (1947c), "Tuvo Repercusión la Distinción Acordada al Dr. Bernardo Houssay", 25 de octubre, pp. 9-10.

La Prensa (1947d), "Prosigue Recibiendo Cordiales Mensajes el Dr. Bernardo Houssay", 29 de octubre, pp. 11-12.

La Prensa (1947e), "Recibió Ayer Nuevas Felicitaciones el Dr. Bernardo Houssay", 30 de octubre, pp. 11-12.

La Voz del Interior. 1947. "Destacadas proyecciones alcanzó el acto inaugural del Instituto de Investigación Médica, cumplido ayer", 30 de marzo, p. 3.

Lewis, Juan (1934), Influencia de la investigación científica sobre la sociedad (folleto), Buenos Aires, Librería y Casa Editoria de A. Guidi Buffarini.

MacDonald, Callum (1980), "The Politic of Intervention: The United States and Argentina, 1941-1946", Journal of Latin American Studies, 12 (2), pp. 365-396.

Mangone, Carlos y Warley, Jorge (1984), Universidad y peronismo (1946-1955), Buenos Aires, Centro Editor de América Latina.

Mariscotti, Mario (1985), El secreto atómico de Huemul. Crónica del origen de la energía atómica en la Argentina, Buenos Aires, Sudamericana-Planeta.

Mesa de redacción (1947), "Aclaración", Ciencia e Investigación, 3, p. 130.

Ministerio de Justicia e Instrucción Pública de la Nación (1947), Proyecto de Plan Quinquenal Analítico de la Universidad Nacional de Tucumán 1947. Tomo III: Plan Analítico de la Estructura y Labor de la Facultad de Ciencias Exactas, Puras y Aplicadas en el Quinquenio 1947-1951, Tucumán, Universidad Nacional de Tucumán.
Nature (1946), "Universities of the Argentina: Retirement of Prof. Bernardo A. Houssay", 148, p. 739.

New York Times (1943), "Argentine President Denounced In Chile", 24 de octubre, p. 28.

Orías, Oscar (1947), Carta a Houssay, Córdoba, 4 de febrero de 1947, АMBH.08/6/9169.

Orías, Oscar (1997) [1947], “Objetivos y organización de un Instituto de Investigación Médica”, En: Consejo de Administración del Instituto Mercedes y Martín Ferreyra (ed.), Instituto de Investigación Médica Mercedes y Martín Ferreyra, s/c: s/e. pp. 16-19.

Ortiz, Eduardo (1996), "Army and Science in Argentina: 1850-1950", En: Forman, P. y Sanchez-Ron, J. M. (eds.), National Military Establishments and the Advancement of Science and Tecnology, Dordrecht, Kluwer Academic Publishers. pp. 153-184.

Parodi, Armando (2006), "Leloir, su vida y su ciencia", Ciencia Hoy, 16 (94), pp. 20-33.

Presidencia de la Nación (1953), 2 Plan Quinquenal, Buenos Aires, Subsecretaría de Informaciones.

Ramacciotti, Karina (2009), La política sanitaria del peronismo, Buenos Aires, Biblos.

Rouquié, Alain (1982) [1978], Poder militar y sociedad política en la Argentina. II. 1943-1973, Buenos Aires, Emecé Editores.

Sauberán, Juan B. (1936), Carta a Bernardo Houssay, Buenos Aires, 10 de julio, Archivo de la AAPC, legajo de la Fundación Sauberán para el Fomento de las Investigaciones en Fisiología.

Science (1943), "Declaration of Citizens of Argentina", 98, pp. 467468.

Science (1944), "The Institute of Biology and Experimental Medicine at Buenos Aires", 99, pp. 360-361.

Science (1945), "The Houssay Journal Fund", 102, p. 161.

Schvarzer, Jorge (1991), Empresarios del pasado. La Unión Industrial Argentina, Buenos Aires, Imago Mundi.

Universidad (1952), "Declaración del Consejo Nacional de Investigaciones Técnicas y Científicas sobre la misión de la ciencia y la técnica en la Argentina Justicialista (Resolución adoptada en la sesión del 8 de abril de 1952)", (25), pp. 387-390.

Taquini, Alberto (1981), "Bernardo Houssay: cómo lo conocí y cómo lo recuerdo", En: Foglia, V. y Deulofeu, V. (eds.), Bernardo A. Houssay. Su vida y su obra 1887-1971, Buenos Aires, Academia Nacional de Ciencias Exactas, Físicas y Naturales. pp. 169-175.

Varsavsky, Oscar (1969), Ciencia, política y cientificismo, Buenos Aires, Centro Editor de América Latina.

Waterman, Alan (1960), “Introduction”, pp. vii-xxvi. En: Bush, V., Science, the Endless Frontier, Washington, D.C., National Science Foundation.

Zanatta, Loris (2009), Breve historia del peronismo clásico, Buenos Aires, Sudamericana. 